\title{
Information flow in supply chain: A fuzzy TOPSIS parameters ranking
}

\author{
Farnoush Farajpour ${ }^{\mathrm{a}}$ and Amir Yousefli ${ }^{\mathrm{b}}$
}

${ }^{a}$ Department of Information Technology Management, Allameh Tabataba'i University, Tehran, Iran ${ }^{b}$ Department of Industrial Management, Imam Khomeini International University, Qazvin, Iran

\begin{tabular}{l}
\hline C H R O N I C L E \\
\hline Article history: \\
Received March 2, 2017 \\
Received in revised format June \\
10, 2017 \\
Accepted July 292017 \\
Available online \\
August 12017 \\
\hline Keywords: \\
Supply chain \\
Information flow \\
Fuzzy TOPSIS
\end{tabular}

\section{Introduction}

Information sharing management is a critical issue for the performance of either an organization or a supply chain. Researches show that sharing information properly in a supply chain leads to a significant reduction in delays, inventory costs, safety stock level and its associated costs. Information management prominence in supply chain makes the "degree of information sharing" as a useful index in managerial decisions. Moreover, in order to reach an integrated supply chain, being aware of different aspects of information flow helps the managers identify their strengths and weaknesses and take appropriate actions to reinforce or correct them. Also, from collaboration point of view, having information of demands, manufacturing, inventories and orders in hand is a vital need to improve

* Corresponding author. Tel: +98-28-3390-1656

E-mail address: yousefli@soc.ikiu.ac.ir (A. Yousefli)

(C) 2018 Growing Science Ltd. All rights reserved. doi: $10.5267 /$ j.uscm.2017.8.001

\begin{abstract}
Flow of information in supply chain is as prominent as material and financial flows and among these three aspects of a supply chain, information flow could be of great importance since it provides a basis for a steady flow of goods and finance as well. To help managers control the flow of information in an effective way, first, the parameters which affect the flow of information should be determined. Then, if the parameters can be controlled carefully, the information will be shared correctly and in a timely manner among supply chain members. This paper identifies the influencing parameters on proper flow of information in supply chain and provides a list of parameters based on the literature as well as the industrial and academic experts' opinions. Afterwards, in order to define the degree of importance for each parameter from the experts' perspective, fuzzy TOPSIS method is employed and the parameters are ranked based on three criteria, namely "measurability", "being illustrative" and "parameters relevancy" to the issue of information flow. The research findings show that "Supply Chain Hardware Capabilities", "Supply Chain Network Infrastructure", "Information Software Capabilities", "Information Sharing Timeliness", "Information Recency" and "Organizational Rewards" received the highest priorities, while "Power of Internal and Inter-personal Communications", "Users' Trust" and "Users' Tendency" were standing at the bottom of this ranking. The results of this research could be employed as an input for strategy development process for supply chain information management activities. Thus, the awareness of each parameter's importance in proper flow of information, helps us make appropriate strategies to improve information management in the supply chain.
\end{abstract}


supply chain members' collaborative actions and to materialize the concept of joint decision making (Heydari, 2014). Furthermore, the state of information flow in supply chain could be a guideline for making investments in information systems and integrated systems implementation projects. It will also be useful in before-after and gap analysis in information technology (IT) projects and from a wider perspective, the degree of information sharing could be employed as an input for making strategic decisions and policy making in organizations and supply chains. On the way to manage flow of information in a supply chain, being aware of the parameters which affect information flow is the most important issue. Supply chain managers' unawareness about such parameters, in addition to the ambiguous nature of the issue caused the managers to fail in reaching a clear understanding of information flow status in supply chain. Therefore, in this paper, we aim to, firstly, identify influencing parameters on information flow in supply chain using previous works in the literature as well as academic and industry experts' opinions, and then, we will determine the relative importance of the parameters by means of fuzzy TOPSIS method and the experts' knowledge.

In next section, the literature of information flow in supply chain will be reviewed and then, in section 3 we will have a look on the research methodology. Developed ranking model is proposed in section 4. Discussion about research findings is provided in section 5 and section 6 includes the conclusion and some insights for future research.

\section{Literature review}

Among the studies conducted on the subject of information flow in supply chain, Barut et al. (2002) considered the extent and intensity of information sharing as two main factors which affect the flow of information in supply chain. They proposed an assessment model to evaluate the degree of cooperation in supply chain. Shore and Venkatachalam (2003) developed a model in which they used Analytical Hiererchical Process (AHP) (Saaty, 2008) to define the priorities of two main parameters, collaboration and infrastructure capability, and four sub-criteria extracted from the literature. Li et al. (2005) proposed six criteria for supply chain activities evaluation including information sharing and information quality. The six criteria affect two other parameters, namely delivery dependability and time to market. They explained that information flow could include different types of information such as strategic information, logistics information and customer information. Lages et al. (2005) considered the amount of information flow, means frequency and duration of sharing information, containing three criteria: 1) frequency of discussion about strategic issues, 2) sharing confidential information, and 3) frequency of talking to the suppliers about business strategies. They developed a metric to evaluate information quality, as an aspect of information sharing, among import and export companies. They analyzed the data statistically to show that as the quality of information increases, its positive impact on information flow and long term policies, as a result of business partners' satisfaction, will increase as well. Li and Lin (2006) investigated the relationship between information sharing and information quality, as dependent parameters, and intra-organizational relationship, organizational facilitators and environmental uncertainties, as independent parameters. They employed multivariate regression to determine the coefficients and degree of influence of parameters to indicate the desired level of information flow. Fawcett et al. (2007) mentioned "connectivity" and "willingness" as two main parameters which affect the flow of information. Arshinder and Deshmukh (2007) referred to collaboration approach in supply chain including mechanisms such as contract, information sharing, information technology and joint plans. Regarding the importance of inventory level aspect, six indices were introduced for information sharing mechanism. Martínez-Olvera (2008) proposed a model to determine upward or downward trends in performance of information management and information sharing systems, using Shannon's entropy measurement. Considering the uncertainties of supply chain activities, Gong and Zhang (2010) employed soft systems theory to develop a model for information flow evaluation in supply chain. Xiao-rong and Sui-cheng (2010) developed a model to determine the relationships between manufacturer's internal factors, information sharing and information quality, and finally and they tested the model for a case study. They mentioned "information sharing expectations" 
and "information sharing behavior" as two important factors in information flow. They used statistical hypothesis testing to determine the relationships between the variables. Yang and Maxwell (2011) reviewed the literature of information flow in government institutions. They investigated the influencing parameters from three perspectives: inter-personal, inter-organizational an intraorganizational. They mentioned information extent, type and value, organizational structure, members' belief, rewards and incentives, trust, power game, information technology, social networks and social identity, as the main parameters of intra-organizational information sharing. From inter-organizational perspective, factors such as organizational boundaries, bureaucracy, culture, competitive interests, rewards, trust and information technology capabilities are named as influencing parameters. Yang (2012) developed a model using Analytical Network Process (ANP) to evaluate the information flow capability among supply chain partners. He classified the parameters in three main categories, namely organizational culture, leadership and information technology. Integrated information technologies, internal integration, information quality and sharing costs and benefits among members were mentioned by Baihaqi and Sohal (2013) as the main parameters which influence the flow of information. They illustrated that the first two factors were related directly and positively to information sharing, while the next two factors had no influence on it. De Almeida et al. (2015) mentioned factors such as communication, collaboration, and trust among members of the supply chain lack of which could result in weak flow of information. Information quality is mentioned by Kembro and Selviaridis (2015) as one of the most important issues of information flow which could be determined by accuracy, timeliness, credibility and proper formatting of information.

Although the parameters which affect the flow of information in supply chain are introduced in different papers, no comprehensive investigation on such factors has been provided in literature. So, in this paper a thorough investigation is performed on the influencing parameters on information flow in supply chain based on the literature as well as the industry and academic experts' knowledge. A complete list of parameters is provided and fuzzy TOPSIS method is employed to prioritize them.

\section{Research methodology}

In this research, first, we review the literature to extract the list of parameters which influence on the flow of information in supply chain and then, we employed the experts' knowledge to rank the parameters. Since the required data for parameters ranking is mostly based on the industry and academic experts' knowledge and also, due to having few number of people who have enough knowledge and expertise in the area of information management in supply chain, judgmental and purposive sampling is employed. Then, regarding the qualitative nature of such knowledge, the best sample sizes in qualitative researches was investigated. In different researches of various subjects, the sample numbers range from 6 to 12 and 18 and in more complex cases to 20 (Skulmoski et al., 2007; Guest et al., 2006; Patton, 2002; Marshall, 1996; Bernard, 2011; Morse, 1994; Kuzel, 1992; Bertaux; 1981). In this research, despite having a rich sample and working with the experts with highest degree of expertise in the field of study, the quantity of 30 was considered as the minimum sample size. Each questionnaire was made up of two parts: paired comparison table of parameters criteria and the parameters evaluation table subject to those criteria. Finally, 34 questionnaires were returned out of 50 questionnaires given to the experts. "Measurability", "being illustrative" and "relevancy" are three criteria towards which the parameters are prioritized. The parameters that receive the highest priorities have three characteristics; they are highly related to the subject of information sharing in supply chain, measurable in practice by means of quantitative or qualitative measures, and also, easily understood by the managers. Such parameters are manageable and supply chain managers could improve the information flow by planning to enhance them. So, the experts were asked to evaluate the parameters towards the aforementioned criteria using linguistic variables "very low", "low", "medium", "high" and "very high". Finally, fuzzy TOPSIS method is utilized to analyze the results and to rank the information flow influencing parameters. In this research, identifying and ranking the parameters which 
affect flow of information in supply chain is performed via two main phases: 1) influencing parameters extraction; 2) parameters ranking by fuzzy TOPSIS. These two phases will be discussed hereafter.

\section{1) Influencing parameters extraction}

In this phase, the parameters which have influence on information flow in supply chain are determined based on the literature review and they are validated by the experts.

Table 1

List of influencing parameters on information flow in supply chain

\begin{tabular}{|c|c|c|c|}
\hline Code & Parameter & Definition & Reference \\
\hline$F 1$ & $\begin{array}{l}\text { Information Content \& } \\
\text { Relevancy }\end{array}$ & $\begin{array}{l}\text { The information shared, is the information needed by the suppliers and } \\
\text { the buyers. }\end{array}$ & Zhou and Benton (2007) \\
\hline$F 2$ & Accuracy & Conformity between the recorded and the actual data values & McCormack (1998) \\
\hline$F 3$ & Timeliness & Availability of information at the required time & Li et al. (2005) \\
\hline F4 & Recency & $\begin{array}{l}\text { The shared information is up to date and compatible with the most recent } \\
\text { changes in documents }\end{array}$ & Rashed et al. (2010) \\
\hline F5 & Frequency & Information sharing and keeping the information up to date, is done on a & Rashed et al. (2010) \\
\hline F6 & Adequacy & All information needed by supply chain members is shared & Li et al. (2005) \\
\hline F7 & Information Credibility & Shared information can be trusted & McCormack (1998) \\
\hline F8 & Assigned Resources & $\begin{array}{l}\text { Amount of resources employed for gathering, analysis and using } \\
\text { information (including people, analyzing software, etc.) }\end{array}$ & Martínez-Olvera (2008) \\
\hline F9 & Users’ Tendency & Users' (employees') tendency for preparing and sharing information & Fawcett et al. (2007) \\
\hline F10 & Users' Trust & $\begin{array}{l}\text { Users' (employees') trust to each other for communicating and sharing } \\
\text { information }\end{array}$ & Yang (2012) \\
\hline F11 & $\begin{array}{l}\text { Information Scope of } \\
\text { Use }\end{array}$ & $\begin{array}{l}\text { How deep into the supply chain network (in either direction of customers } \\
\text { or suppliers) the information is shared and used? }\end{array}$ & Barut et al. (2002) \\
\hline F12 & IT based Ordering & The amount of orders placed using Information Technology & Arshinder and Deshmukh (2007) \\
\hline F13 & Two-way Trust \& & Honesty and two-way trust between supply chain members & $\mathrm{Li}$ and $\mathrm{Lin}(2006)$ \\
\hline F14 & $\begin{array}{l}\text { Sharing Confidential } \\
\text { Information }\end{array}$ & Sharing confidential information between supply chain members & Lages et al. (2005) \\
\hline F15 & Information Refinement & $\begin{array}{l}\text { Sharing selected, categorized and specific part of information (instead of } \\
\text { sharing the whole available information) }\end{array}$ & Zailani et al. (2008) \\
\hline
\end{tabular}

\begin{tabular}{|c|c|c|c|}
\hline F16 & $\begin{array}{l}\text { Supply Chain Partners' } \\
\text { Commitment }\end{array}$ & $\begin{array}{l}\text { All supply chain members are aware of information sharing policies and } \\
\text { plans and they tend to implement these policies using the recommended } \\
\text { procedures, solutions and systems }\end{array}$ & $\mathrm{Li}$ and $\operatorname{Lin}(2006)$ \\
\hline F17 & $\begin{array}{l}\text { Shared Supply Chain } \\
\text { Strategies (Internal) }\end{array}$ & $\begin{array}{l}\text { Supply chain strategies are introduced and implemented in all supply } \\
\text { chain members organizations }\end{array}$ & $\begin{array}{l}\text { Fawcett et al. (2007); Lages et } \\
\text { al. (2005) }\end{array}$ \\
\hline F18 & $\begin{array}{l}\text { Shared Supply Chain } \\
\text { Strategies (External) }\end{array}$ & $\begin{array}{l}\text { Supply chain members frequently discuss together about supply chain } \\
\text { strategies }\end{array}$ & $\begin{array}{l}\text { Fawcett et al. (2007); Lages et } \\
\text { al. (2005) }\end{array}$ \\
\hline F19 & Power of Internal \& & Power of formal and informal groups in the organization & Lages et al. (2005) \\
\hline F20 & Interpersonal Trust & Interpersonal trust for sharing information & Zárraga and Bonache (2003) \\
\hline$F 21$ & Learning Orientation & $\begin{array}{l}\text { The emphasis on organizational learning and knowledge sharing among } \\
\text { employees }\end{array}$ & $\begin{array}{l}\text { Taylor and Wright (2004);Omar } \\
\text { Sharifuddin Syed-Ikhsan and } \\
\text { Rowland (2004); Zárraga and } \\
\text { Bonache (2003) }\end{array}$ \\
\hline$F 22$ & Organizational Rewards & $\begin{array}{l}\text { The rewards and incentives for participating in information sharing } \\
\text { activities }\end{array}$ & Kim and Lee (2006) \\
\hline$F 23$ & Hardware Capabilities & $\begin{array}{l}\text { - Speed of information exchange } \\
\text { - Hardware age: best hardware is under one year and the oldest one is more } \\
\text { than five vears old. }\end{array}$ & Arshinder and Deshmukh (2007) \\
\hline$F 24$ & $\begin{array}{l}\text { Information Software } \\
\text { Capabilities }\end{array}$ & $\begin{array}{l}\text { Existence of shared information systems between supply chain partners } \\
\text { and updating the recorded information upon changes }\end{array}$ & Fawcett et al. (2007) \\
\hline$F 25$ & Network Infrastructure & Existence of computer network among supply chain members & Yang (2012) \\
\hline$F 26$ & IT Acceptance & $\begin{array}{l}\text { Acceptance to use information technology by supply chain members and } \\
\text { their employees }\end{array}$ & Arshinder and Deshmukh (2007) \\
\hline$F 27$ & Benefits & Benefits gained from information sharing & Rashed et al. (2010) \\
\hline$F 28$ & Costs & The costs of information sharing & Rashed et al. (2010) \\
\hline$F 29$ & Connectivity & $\begin{array}{l}\text { How fast the information is updated and exchanged among supply chain } \\
\text { members? }\end{array}$ & Fawcett et al. (2007) \\
\hline F30 & Intensity & $\begin{array}{l}\text {-How extended is the time horizon for information sharing? } \\
\text {-How much is the shared information employed in making plans in the } \\
\text { supply chain? }\end{array}$ & Carr and Pearson (1999) \\
\hline$F 31$ & Accessibility & $\begin{array}{l}\text { The degree of availability and accessibility of information among supply } \\
\text { chain partners }\end{array}$ & Zhou and Benton (2007) \\
\hline F32 & Consistency & When the representation of the data values is the same in all cases & Zailani et al. (2008) \\
\hline
\end{tabular}


As mentioned in section 2, although many researches have been conducted on the subject of information flow in supply chain, lack of a comprehensive view on the influencing parameters is evident and most papers considered a few number of parameters in their investigations. At the end of this phase, 32 parameters were identified. The definitions of parameters are presented in Table 1 .

\section{2) Parameters ranking by fuzzy TOPSIS}

Importance of determining the priorities of parameters which affect flow of information in supply chain will be more evident when making strategic information plans or deciding about information sharing activities in supply chain. The managers wish to invest on projects and activities with the highest efficiency and effectiveness. So, providing them with a ranking for the influencing parameters on information flow would help the managers to make more rational and effective investments. The main steps to rank the parameters are as follows:

i. $\quad$ Defining criteria weights;

ii. $\quad$ Providing experts' evaluation matrices;

iii. Quantifying the qualitative matrices;

iv. Aggregating the matrixes;

v. Normalizing and making weighted matrix;

vi. Calculating positive and negative ideals;

vii. Calculating distances and ranking the parameters;

In section 4 the aforementioned steps will be explained in detail.

\section{Fuzzy TOPSIS model for parameters ranking}

As mentioned before, 32 parameters obtained from the literature are prioritized towards three criteria, namely "measurability", "being illustrative" and "relevancy". Due to the vagueness inherited in qualitative nature of the parameters, it will be too complex to quantify their values directly. Therefore, the experts were asked to make their assessment using linguistic expressions "very low", "low", "medium", "high" and "very high". Validity of the questionnaire in this phase was confirmed by academic experts and also it was considered reliable due to having the Cronbach's alpha of 0.87 . Then, the linguistic terms are quantified in the form of triangular fuzzy numbers. Finally, a unique matrix will be obtained which will be used as the input for fuzzy TOPSIS method. Hereafter, the main steps for ranking the influencing parameters on information flow in supply chain will be discussed.

\subsection{Defining criteria weights}

As one of preliminary steps in fuzzy TOPSIS ranking, relative importance of each should be determined. Here, to make comparison between "measurability", "being illustrative" and "relevancy", paired comparison method is utilized and the experts were asked to compare the criteria pairwise. From total number of 50, 34 questionnaires were returned by the experts, among which 31 questionnaires demonstrated an inconsistency ratio of less than 0.1 and were used for the rest of process.

The questionnaire included a matrix (like Table 2) and the expert was asked to put a number from 1 to 9 in the intersection of criterion " $a$ " in row and criterion " $b$ " in column, in case he/she reckon that "a" is more important than " $b$ ". When relative importance of " $a$ " is significantly more than " $b$ " the number will be closer to 9, and vice versa. In contrast, when criterion " $a$ " is less important than " $b$ ", a number between $\frac{1}{9}$ and 1 should be selected. 
Table 2

Paired comparison matrix

\begin{tabular}{llll}
\hline & Measurability & Being Illustrative & Relevancy \\
\hline $\begin{array}{l}\text { Measurability } \\
\text { Being Illustrative }\end{array}$ & 1 & & \\
Relevancy & & 1 & 1 \\
\hline
\end{tabular}

$P_{k}$ is paired comparison matrix completed by the expert $k(k=1,2, \ldots, K)$ and it is shown as Eq. (1).

$$
\left.P_{k}=\begin{array}{rcc}
\text { Measurability } & \text { Being Illustrative } & \text { Relevancy } \\
\text { Measurability } & \text { Being Illustrative } \\
\text { Relevancy } & x_{12}^{k} & x_{13}^{k} \\
x_{21}^{k} & 1 & x_{23}^{k} \\
x_{31}^{k} & x_{32}^{k} & 1
\end{array}\right]
$$

where, $x_{j i}^{k}=\frac{1}{x_{i j}^{k}} ; i, j=1,2,3$.

In order to aggregate the experts' paired comparison matrixes, each matrix should be firstly normalized using Eq. (2):

$$
a_{i j}^{k}=\frac{x_{i j}^{k}}{\sum_{i=1}^{3} x_{i j}^{k}}
$$

\begin{tabular}{|c|c|c|c|c|}
\hline & & Measurability & Being Illustrative & Relevancy \\
\hline \multirow{3}{*}{$P_{k}^{n}=$} & Measurability & $a_{11}^{k}$ & $a_{12}^{k}$ & $a_{13}^{k}$ \\
\hline & Being Illustrative & $a_{21}^{k}$ & $a_{22}^{k}$ & $a_{23}^{k}$ \\
\hline & Relevancy & $a_{31}^{k}$ & $a_{32}^{k}$ & $a_{33}^{k}$ \\
\hline
\end{tabular}

$P_{k}^{n}$ is the normalized paired comparison matrix related to the expert $k$ and it is shown as Eq. (3):

To obtain aggregated paired comparison matrix, geometric mean of normalized matrixes of $K$ experts is calculated as per Eq. (4) (Saaty, 2008):

$$
r_{i j}=\sqrt[K]{\prod_{k=1}^{K} a_{i j}^{k}}
$$

$P$ is the aggregated paired comparison matrix of $K$ experts $(K=31)$ and it is shown as Eq. (5):

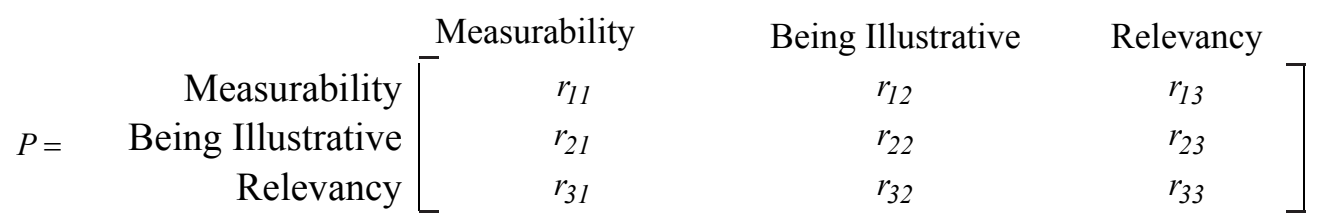

So, in this paper, $P$ is obtained as follows: 


\begin{tabular}{|c|c|c|c|c|}
\hline \multirow{4}{*}{$P=$} & & Measurability & Being Illustrative & Relevancy \\
\hline & Measurability & 0.29 & 0.34 & 0.27 \\
\hline & Being Illustrative & 0.18 & 0.21 & 0.24 \\
\hline & Relevancy & 0.39 & 0.31 & 0.36 \\
\hline
\end{tabular}

Using Eq. (6), the weights for "measurability", "being illustrative" and "relevancy" were calculated as $0.34,0.24$ and 0.41 , respectively. So, the criteria weights vector was obtained as $W=(0.34,0.24,0.41)$.

\subsection{Providing experts' evaluation matrix}

In this step, experts' assessment matrixes, in which each parameter was evaluated towards three criteria using linguistic variables, are received. Each assessment matrix is labeled as $D^{k}$ and it is shown as follows:

$$
D^{k}=\left[b_{i j}^{k}\right]_{32 \times 3}
$$

where $b_{i j}^{k}(i=1,2, \ldots, 32 ; j=1,2,3)$ is a linguistic expression "very low", "low", "medium", "high" or "very high". These linguistic variables should be quantified through next steps.

\subsection{Quantifying the qualitative matrixes}

Here, each linguistic expression is mapped to a triangular fuzzy number according to Fig. 1.

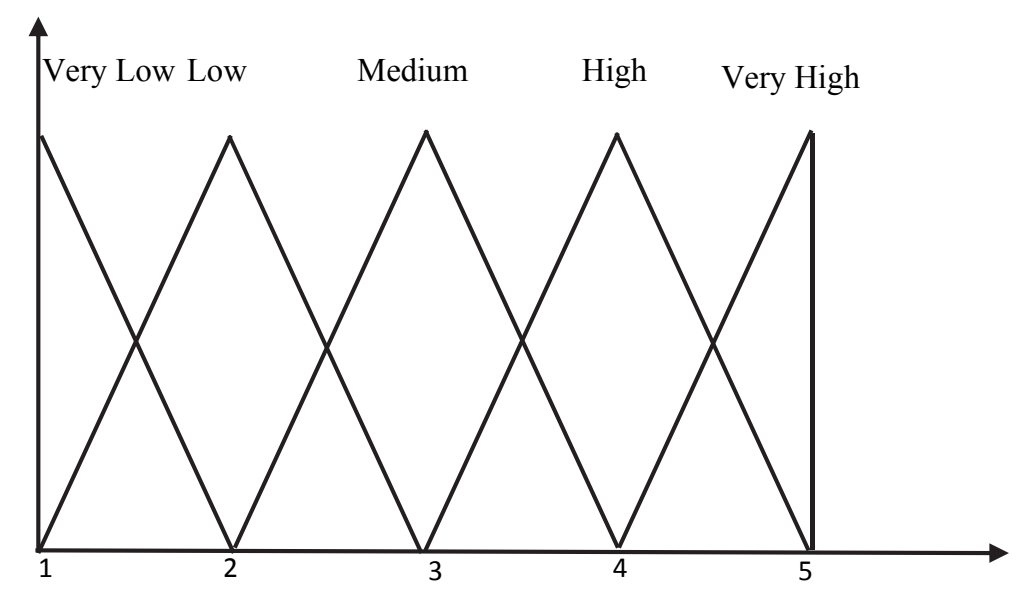

Fig. 1. Triangular fuzzy numbers

So, the assessment matrix $D^{k}$ is transformed to a fuzzy assessment matrix $\left(\widetilde{D}^{k}\right)$ as follows:

$$
\widetilde{D}^{k}=\left[\widetilde{b}_{i j}^{k}\right]_{32 \times 3}
$$

where, each $\widetilde{b}_{i j}^{k}=\left(b_{i j L}^{k}, b_{i j M}^{k}, b_{i j R}^{k}\right),(i=1,2, \ldots, 32 ; j=1,2,3)$ is a triangular fuzzy number.

\subsection{Aggregating the matrixes}

Having the assessment matrixes quantified, 37 (number of questionnaires) fuzzy matrixes should be aggregated in a unique matrix. To this end, fuzzy average is utilized as per Eq. (9) (Zimmermann, 2011): 


$$
\widetilde{b}_{i j}=\left(\frac{\sum_{k=1}^{K} b_{i j L}^{k}}{K}, \frac{\sum_{k=1}^{K} b_{i j M}^{k}}{K}, \frac{\sum_{k=1}^{K} b_{i j R}^{k}}{K}\right) ; j=1,2, \ldots, 32 ; j=1,2,3
$$

So, aggregated fuzzy matrix $\widetilde{D}$ is obtained as follows:

$$
\widetilde{D}=\left[\widetilde{b}_{i j}\right]_{32 \times 3}
$$

where $\tilde{b}_{i j}=\left(b_{i j}^{L}, b_{i j}^{M}, b_{i j}^{R}\right)$ is the triangular fuzzy number related to evaluation of parameter $i$ towards criterion $j$, which is obtained from aggregation of the experts' evaluations.

\begin{tabular}{|c|c|c|c|}
\hline & Measurability & Being Illustrative & Relevancy \\
\hline$F 1$ & $(2.63,3.63,4.5)$ & $(3.5,4.5,4.88)$ & $(3.88,4.88,5)$ \\
\hline$F 2$ & $(2.75,3.75,4.63)$ & $(3.75,4.75,5)$ & $(4,5,5)$ \\
\hline$F 3$ & $(3.75,4.75,5)$ & $(3.88,4.88,5)$ & $(3.63,4.5,4.63)$ \\
\hline$F 4$ & $(3.63,4.63,5)$ & $(3.88,4.88,5)$ & $(3.63,4.5,4.63)$ \\
\hline$F 5$ & $(3.25,4.25,4.75)$ & $(3.63,4.63,4.88)$ & $(3,3.75,4.13)$ \\
\hline F6 & $(2.5,3.5,4.25)$ & $(3.38,4.38,4.75)$ & $(3.5,4.38,4.63)$ \\
\hline$F 7$ & $(2.38,3.38,4.13)$ & $(3.13,4.13,4.5)$ & $(3.5,4.5,4.88)$ \\
\hline$F 8$ & $(3.13,4.13,4.63)$ & $(3.25,4.13,4.5)$ & $(2.63,3.63,4.5)$ \\
\hline$F 9$ & $(2,3,3.88)$ & $(3.13,4.13,4.63)$ & $(3,4,4.5)$ \\
\hline F10 & $(2.13,3.13,4)$ & $(3.13,4.13,4.63)$ & $(3,4,4.5)$ \\
\hline F11 & $(2.88,3.88,4.63)$ & $(3.88,4.88,5)$ & $(3.38,4.38,4.88)$ \\
\hline$F 12$ & $(3.38,4.38,5)$ & $(3.88,4.88,5)$ & $(2.88,3.88,4.63)$ \\
\hline$F 13$ & $(1.75,2.75,3.75)$ & $(3.63,4.63,4.88)$ & $(3.75,4.75,5)$ \\
\hline$F 14$ & $(2.25,3.25,4.13)$ & $(3.63,4.63,5)$ & $(3.75,4.75,5)$ \\
\hline$F 15$ & $(2.38,3.38,4.38)$ & $(3.38,4.38,4.75)$ & $(2.63,3.63,4.5)$ \\
\hline$F 16$ & $(2,3,4)$ & $(3.5,4.5,4.88)$ & $(3.63,4.63,5)$ \\
\hline$F 17$ & $(2.38,3.25,4.25)$ & $(3.13,4.13,4.88)$ & $(3.13,4.13,4.63)$ \\
\hline$F 18$ & $(2,2.88,3.88)$ & $(3.13,4.13,4.75)$ & $(3.38,4.38,4.75)$ \\
\hline$F 19$ & $(2,2.88,3.88)$ & $(3.25,4.25,4.63)$ & $(3.13,4.13,4.63)$ \\
\hline$F 20$ & $(1.63,2.5,3.5)$ & $(3.63,4.63,5)$ & $(3.25,4.25,4.75)$ \\
\hline$F 21$ & $(2.25,3.25,4.25)$ & $(3.5,4.5,5)$ & $(3,4,4.5)$ \\
\hline$F 22$ & $(3.63,4.63,5)$ & $(3.88,4.88,5)$ & $(3.5,4.5,4.75)$ \\
\hline$F 23$ & $(3.75,4.75,5)$ & $(3.88,4.88,5)$ & $(4,5,5)$ \\
\hline$F 24$ & $(3.63,4.63,4.75)$ & $(3.88,4.88,5)$ & $(3.88,4.88,5)$ \\
\hline$F 25$ & $(3.75,4.75,5)$ & $(3.88,4.88,5)$ & $(3.88,4.88,5)$ \\
\hline$F 26$ & $(2.25,3.13,4)$ & $(3.5,4.5,4.88)$ & $(3.88,4.88,5)$ \\
\hline$F 27$ & $(2.38,3.38,4.25)$ & $(3.38,4.38,4.88)$ & $(3.88,4.88,5)$ \\
\hline$F 28$ & $(3,4,4.63)$ & $(3.63,4.63,5)$ & $(3.88,4.88,5)$ \\
\hline$F 29$ & $(2.88,3.88,4.5)$ & $(3.13,4.13,4.75)$ & $(3.38,4.38,4.88)$ \\
\hline F30 & $(2.38,3.38,4.13)$ & $(2.88,3.88,4.5)$ & $(3.75,4.75,5)$ \\
\hline$F 31$ & $(2.75,3.75,4.75)$ & $(3.75,4.75,5)$ & $(3.75,4.75,5)$ \\
\hline$F 32$ & $(3.13,4.13,4.63)$ & $(3.63,4.63,4.88)$ & $(3.88,4.88,5)$ \\
\hline
\end{tabular}

By taking three aforementioned steps, aggregated fuzzy assessment matrix is obtained as per Eq. (11).

\subsection{Normalizing and making weighted matrix}

Having the assessment matrixes aggregated, $\widetilde{D}$ should be normalized now. To this end, Eq. (12) is employed (Chen, 2000):

$$
\widetilde{c}_{i j}=\left(\frac{b_{i j}^{L}}{R_{j}}, \frac{b_{i j}^{M}}{R_{j}}, \frac{b_{i j}^{R}}{R_{j}}\right)
$$

where $R_{j}=\max _{i} b_{i j}^{R}$.

So, the normalized assessment matrix $N \widetilde{D}$ is shown as follows:

$$
N \widetilde{D}=\left[\widetilde{c}_{i j}\right]_{32 \times 3}
$$

Next step is to calculate weighted assessment matrix $\widetilde{V}=\left[\widetilde{v}_{i j}\right]_{32 \times 3}$, by multiplying $N \widetilde{D}$ by weights vector $W$, which was obtained in section 4.1 (Chen, 2000):

$$
\tilde{v}_{i j}=\tilde{c}_{i j}(.) w_{j} ; i=1,2, \ldots, 32 ; j=1,2,3
$$

So, weighted assessment matrix is obtained as per Eq. (15). 


\subsection{Calculating positive and negative ideals}

Taking into account that all three criteria in this paper (measurability, being illustrative and relevancy) have positive impacts, the maximum and the minimum scores for each criterion in matrix (15) are considered as positive and negative ideal solutions, respectively. It is noteworthy that this is done using fuzzy maximum and minimum operators (Zimmermann, 2011).

\begin{tabular}{l|ccc|} 
& Measurability & Being Illustrative & Relevancy \\
$F 1$ & $(0.18,0.25,0.31)$ & $(0.17,0.22,0.24)$ & $(0.32,0.4,0.41)$ \\
$F 2$ & $(0.19,0.26,0.32)$ & $(0.18,0.23,0.24)$ & $(0.33,0.41,0.41)$ \\
$F 3$ & $(0.26,0.33,0.34)$ & $(0.19,0.24,0.24)$ & $(0.3,0.37,0.38)$ \\
$F 4$ & $(0.25,0.32,0.34)$ & $(0.19,0.24,0.24)$ & $(0.3,0.37,0.38)$ \\
$F 5$ & $(0.22,0.29,0.33)$ & $(0.18,0.23,0.24)$ & $(0.25,0.31,0.34)$ \\
$F 6$ & $(0.17,0.24,0.29)$ & $(0.16,0.21,0.23)$ & $(0.29,0.36,0.38)$ \\
$F 7$ & $(0.16,0.23,0.28)$ & $(0.15,0.2,0.22)$ & $(0.29,0.37,0.4)$ \\
$F 8$ & $(0.22,0.28,0.32)$ & $(0.16,0.2,0.22)$ & $(0.22,0.3,0.37)$ \\
$F 9$ & $(0.14,0.21,0.27)$ & $(0.15,0.2,0.23)$ & $(0.25,0.33,0.37)$ \\
$F 10$ & $(0.15,0.22,0.28)$ & $(0.15,0.2,0.23)$ & $(0.25,0.33,0.37)$ \\
$F 11$ & $(0.2,0.27,0.32)$ & $(0.19,0.24,0.24)$ & $(0.28,0.36,0.4)$ \\
$F 12$ & $(0.23,0.3,0.34)$ & $(0.19,0.24,0.24)$ & $(0.24,0.32,0.38)$ \\
$F 13$ & $(0.12,0.19,0.26)$ & $(0.18,0.23,0.24)$ & $(0.31,0.39,0.41)$ \\
$F 14$ & $(0.16,0.22,0.28)$ & $(0.18,0.23,0.24)$ & $(0.31,0.39,0.41)$ \\
$F 15$ & $(0.16,0.23,0.3)$ & $(0.16,0.21,0.23)$ & $(0.22,0.3,0.37)$ \\
$F 16$ & $(0.14,0.21,0.28)$ & $(0.17,0.22,0.24)$ & $(0.3,0.38,0.41)$ \\
$F 17$ & $(0.16,0.22,0.29)$ & $(0.15,0.2,0.24)$ & $(0.26,0.34,0.38)$ \\
$F 18$ & $(0.14,0.2,0.27)$ & $(0.15,0.2,0.23)$ & $(0.28,0.36,0.39)$ \\
$F 19$ & $(0.14,0.2,0.27)$ & $(0.16,0.21,0.23)$ & $(0.26,0.34,0.38)$ \\
$F 20$ & $(0.11,0.17,0.24)$ & $(0.18,0.23,0.24)$ & $(0.27,0.35,0.39)$ \\
$F 21$ & $(0.16,0.22,0.29)$ & $(0.17,0.22,0.24)$ & $(0.25,0.33,0.37)$ \\
$F 22$ & $(0.25,0.32,0.34)$ & $(0.19,0.24,0.24)$ & $(0.29,0.37,0.39)$ \\
$F 23$ & $(0.26,0.33,0.34)$ & $(0.19,0.24,0.24)$ & $(0.33,0.41,0.41)$ \\
$F 24$ & $(0.25,0.32,0.33)$ & $(0.19,0.24,0.24)$ & $(0.32,0.4,0.41)$ \\
$F 25$ & $(0.26,0.33,0.34)$ & $(0.19,0.24,0.24)$ & $(0.32,0.4,0.41)$ \\
$F 26$ & $(0.16,0.22,0.28)$ & $(0.17,0.22,0.24)$ & $(0.32,0.4,0.41)$ \\
$F 27$ & $(0.16,0.23,0.29)$ & $(0.16,0.21,0.24)$ & $(0.32,0.4,0.41)$ \\
$F 28$ & $(0.21,0.28,0.32)$ & $(0.18,0.23,0.24)$ & $(0.32,0.4,0.41)$ \\
$F 29$ & $(0.2,0.27,0.31)$ & $(0.15,0.2,0.23)$ & $(0.28,0.36,0.4)$ \\
$F 30$ & $(0.16,0.23,0.28)$ & $(0.14,0.19,0.22)$ & $(0.31,0.39,0.41)$ \\
$F 31$ & $(0.19,0.26,0.33)$ & $(0.18,0.23,0.24)$ & $(0.31,0.39,0.41)$ \\
$F 32$ & $(0.22,0.28,0.32)$ & $(0.18,0.23,0.24)$ & $(0.32,0.4,0.41)$
\end{tabular}

Positive and negative ideal solutions are calculated as per Eq. (16) and Eq. (17).

$$
\begin{aligned}
& \widetilde{F}^{*}=\left\{\widetilde{F}_{1}^{*}, \widetilde{F}_{2}^{*}, \widetilde{F}_{3}^{*}\right\} \\
& \widetilde{F}_{j}^{*}=\max _{i} \widetilde{v}_{i j}=\left(\max _{i} v_{i j}^{L}, \max _{i} v_{i j}^{M}, \max _{i} v_{i j}^{R}\right) \\
& \widetilde{F}^{-}=\left\{\widetilde{F}_{1}^{-}, \widetilde{F}_{2}^{-}, \widetilde{F}_{3}^{-}\right\} \\
& \widetilde{F}_{j}^{-}=\min _{i} \widetilde{v}_{i j}=\left(\min _{i} v_{i j}^{L}, \min _{i} v_{i j}^{M}, \min _{i} v_{i j}^{R}\right)
\end{aligned}
$$

Therefore, positive and negative ideal solutions for matrix (15) are as follows:

$$
\begin{aligned}
& \widetilde{F}^{*}=\{(0.26,0.33,0.34),(0.19,0.24,0.24),(0.33,0.41,0.41)\} \\
& \widetilde{F}^{-}=\{(0.11,0.17,0.24),(0.14,0.19,0.22),(0.22,0.30,0.34)\}
\end{aligned}
$$

\subsection{Calculating distances and ranking the parameters}

The last step for prioritizing the influencing parameters on information flow in supply chain is to calculate the distance of each parameter from positive and negative ideal solutions. Here, we utilized the concept of distance between two fuzzy numbers (Chen, 2000). So, the distances between each parameter score in each criterion $\left(\widetilde{v}_{i j}\right)$ and positive and negative ideal solutions $\left(\widetilde{F}_{j}^{*}\right.$ and $\left.\widetilde{F}_{j}^{-}\right)$are calculated as follows:

$$
d^{*}\left(\widetilde{v}_{i j}, \widetilde{F}_{j}^{*}\right)=\sqrt{\frac{1}{3}\left[\left(v_{i j}^{L}-F_{j}^{* L}\right)^{2}+\left(v_{i j}^{M}-F_{j}^{* M}\right)^{2}+\left(v_{i j}^{R}-F_{j}^{* R}\right)^{2}\right]}
$$




$$
d^{-}\left(\widetilde{v}_{i j}, \widetilde{F}_{j}^{-}\right)=\sqrt{\frac{1}{3}\left[\left(v_{i j}^{L}-F_{j}^{-L}\right)^{2}+\left(v_{i j}^{M}-F_{j}^{-M}\right)^{2}+\left(v_{i j}^{R}-F_{j}^{-R}\right)^{2}\right]}
$$

Now, having the distances from positive and negative ideal solutions obtained for each parameter in each criterion, total distances of parameter $i$ from positive and negative ideals should be calculated as per Eq. (22) and Eq. (23) (Chen, 2000):

$$
\begin{aligned}
& d_{i}^{*}=\sum_{j=1}^{3} d^{*}\left(\widetilde{v}_{i j}, \widetilde{F}_{j}^{*}\right) \\
& d_{i}^{-}=\sum_{j=1}^{3} d^{-}\left(\widetilde{v}_{i j}, \widetilde{F}_{j}^{-}\right)
\end{aligned}
$$

Employing the Eqs. (20-23) for matrix (15), parameters distances from positive and negative ideal solutions are obtained as it is shown in Table 3.

Table 3

Distances from positive and negative ideal solutions

\begin{tabular}{lrrlcc}
\hline Parameter & $d_{i}^{*}$ & $d_{i}^{-}$ & Parameter & $d_{i}^{*}$ & $d_{i}^{-}$ \\
\hline Information Content \& Relevancy & 0.09 & 0.19 & Shared Supply Chain Strategies (Internal) & 0.18 & 0.11 \\
Accuracy & 0.06 & 0.22 & Shared Supply Chain Strategies (External) & 0.19 & 0.10 \\
Timeliness & 0.03 & 0.25 & Power of Internal \&Inter-personal Communications & 0.20 & 0.08 \\
Recency & 0.04 & 0.24 & Interpersonal Trust & 0.20 & 0.08 \\
Frequency & 0.13 & 0.16 & Learning Orientation & 0.18 & 0.11 \\
Adequacy & 0.14 & 0.14 & Organizational Rewards & 0.04 & 0.24 \\
Information Credibility & 0.15 & 0.13 & Hardware Capabilities & 0.00 & 0.28 \\
Assigned Resources & 0.16 & 0.13 & Information Software Capabilities & 0.02 & 0.26 \\
Users' Tendency & 0.21 & 0.07 & Network Infrastructure & 0.01 & 0.27 \\
Users' Trust & 0.20 & 0.08 & IT Acceptance & 0.12 & 0.16 \\
Information Scope of Use & 0.09 & 0.19 & Benefits & 0.11 & 0.17 \\
IT based Ordering Activities & 0.10 & 0.19 & Costs & 0.06 & 0.22 \\
Two-way Trust \& Honesty & 0.15 & 0.13 & Connectivity & 0.13 & 0.16 \\
Sharing Confidential Information & 0.12 & 0.17 & Intensity & 0.14 & 0.14 \\
Information Refinement & 0.20 & 0.10 & Accessibility & 0.08 & 0.21 \\
Supply Chain Partners' Commitment & 0.15 & 0.14 & Consistency & 0.06 & 0.22 \\
\hline
\end{tabular}

Final ranking of parameters will be done based on total distance index which is calculated as per Eq. (24):

$$
F I_{i}=\frac{d_{i}^{-}}{d_{i}^{-}+d_{i}^{*}}
$$

From Table 3 and Eq. (24), we have total distance indices of parameters as it is shown in Table 4.

Table 4

Total distance indices

\begin{tabular}{lllc}
\hline Parameter & $F I_{i}$ & Parameter & $F I_{i}$ \\
\hline Information Content \& Relevancy & 0.68 & Shared Supply Chain Strategies (Internal) & 0.38 \\
Accuracy & 0.78 & Shared Supply Chain Strategies (External) & 0.34 \\
Timeliness & 0.88 & Power of Internal \&Inter-personal Communications & 0.29 \\
Recency & 0.85 & Interpersonal Trust & 0.30 \\
Frequency & 0.55 & Learning Orientation & 0.38 \\
Adequacy & 0.50 & Organizational Rewards & 0.85 \\
Information Credibility & 0.46 & Hardware Capabilities & 1.00 \\
Assigned Resources & 0.44 & Information Software Capabilities & 0.93 \\
Users' Tendency & 0.25 & Network Infrastructure & 0.97 \\
Users' Trust & 0.28 & IT Acceptance & 0.57 \\
Information Scope of Use & 0.67 & Benefits & 0.61 \\
IT based Ordering Activities & 0.66 & Costs & 0.78 \\
Two-way Trust \& Honesty & 0.47 & Connectivity & 0.56 \\
Sharing Confidential Information & 0.58 & Intensity & 0.49 \\
Information Refinement & 0.33 & Accessibility & 0.72 \\
Supply Chain Partners' Commitment & 0.48 & Consistency & 0.80 \\
\hline
\end{tabular}




\section{Research Findings and Discussion}

After prioritizing 32 parameters which affect the flow of information in supply chain, based on the experts' knowledge and using fuzzy TOPSIS method, parameters ranking scores were obtained as per Table 4. Fig. 2 illustrates the parameters sorted based on their ranking.

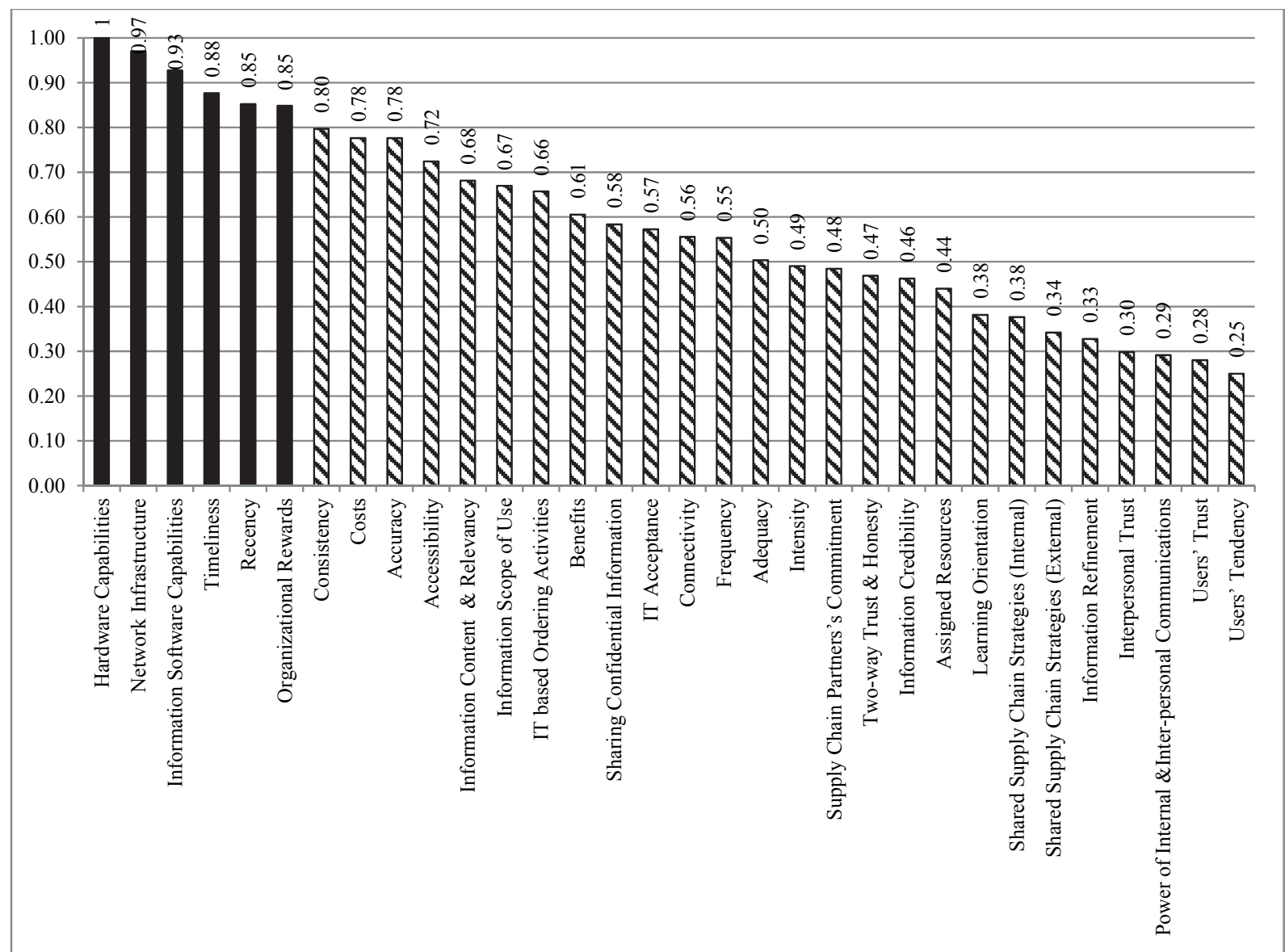

Fig. 2. Parameters ranking

Investigating the parameters ranking, it is significant that six parameters, namely, "Supply Chain Hardware Capabilities", "Supply Chain Network Infrastructure", "Information Software Capabilities", "Information Sharing Timeliness", "Information Recency" and "Organizational Rewards", constitute top $20 \%$ of the ranking. This result magnifies the prominence of information technology in managing, controlling and improving the flow of information in supply chain. Having the business world so competitive today, in order to reach competitive advantage and sufficient agility in ever-changing market, supply chains are inevitably forced to benefit from IT infrastructures and computer networks such as internet, intranets, suppliers' portals and also, integrated software and organizational and interorganizational information systems. In addition to information technology issues, from the experts' point of view, it is very important to have the information shared in proper time and with the recent changes and updates. Moreover, this research demonstrates the importance of personnel motivation by offering rewards for positive contributions to the information sharing activities. Therefore, in case of resources constraints, the managers who aim to enhance information flow in supply chain are recommended to make improvements to the six aforementioned parameters, since, this research shows that improving deficiencies in these parameters will encompass significant influences on information flow in supply chain. 


\section{Conclusion}

Regarding the importance of information flow management and control in supply chain and critical role of proper and effective flow of information to competitiveness of supply chains, in this paper, the influencing parameters on information flow of supply chains are identified and ranked. Without knowing such parameters and their importance it would be hard to make any plan or put any target for future improvements in the area of information flow management in supply chain. So, in this research, first, a list of influencing parameters was extracted by reviewing the literature of information flow in supply chain. Then, industry and academic experts were asked to evaluate the parameters towards three criteria, "measurability", "being illustrative" and "relevancy", using linguistic expressions, "very low", "low", "medium", "high" or "very high". Moreover, they were requested to determine the relative importance of three aforementioned criteria in the form of paired comparison matrix. Finally, the parameters were ranked employing fuzzy TOPSIS method. The results show that six parameters, "Supply Chain Hardware Capabilities", "Supply Chain Network Infrastructure", "Information Software Capabilities", "Information Sharing Timeliness", "Information Recency" and "Organizational Rewards", placed on the top $20 \%$ of the ranking, which illustrates the prominence of information technology as well as employees motivation in information flow management. As an extension of this research readers are encouraged to investigate the way the parameters correlate and how they affect the flow of information in supply chain.

\section{References}

Arshinder, K. A., \& Deshmukh, S. G. (2007). Coordination in supply chains: an evaluation using fuzzy logic. Production Planning \& Control, 18(5), 420-435.

Baihaqi, I., \& Sohal, A. S. (2013). The impact of information sharing in supply chains on organisational performance: an empirical study. Production Planning \& Control, 24(8-9), 743-758.

Barut, M., Faisst, W., \& Kanet, J. J. (2002). Measuring supply chain coupling: an information system perspective. European Journal of Purchasing \& Supply Management, 8(3), 161-171.

Bernard, H. R. (2011). Research methods in anthropology: Qualitative and quantitative approaches. Rowman Altamira.

Bertaux, D. (1981). From the life-history approach to the transformation of sociological practice.In Biography and society: The life history approach in the social sciences, ed. by D. Bertaux, 29-45. London: Sage.

Carr, A. S., \& Pearson, J. N. (1999). Strategically managed buyer-supplier relationships and performance outcomes. Journal of operations management, 17(5), 497-519.

Chen, C. T. (2000). Extensions of the TOPSIS for group decision-making under fuzzy environment. Fuzzy sets and systems, 114(1), 1-9.

de Almeida, M. M. K., Marins, F. A. S., Salgado, A. M. P., Santos, F. C. A., \& da Silva, S. L. (2015). Mitigation of the bullwhip effect considering trust and collaboration in supply chain management: a literature review. The International Journal of Advanced Manufacturing Technology, 77(1-4), 495-513.

Fawcett, S. E., Osterhaus, P., Magnan, G. M., Brau, J. C., \& McCarter, M. W. (2007). Information sharing and supply chain performance: the role of connectivity and willingness. Supply Chain Management: An International Journal, 12(5), 358-368.

Gong, K., \& Zhang, X. (2010, November). Applying bijective soft set in assessment of supply chain information sharing. In Information Management, Innovation Management and Industrial Engineering (ICIII), 2010 International Conference on (Vol. 1, pp. 168-171). IEEE.

Guest, G., Bunce, A., \& Johnson, L. (2006). How many interviews are enough? An experiment with data saturation and variability. Field methods, 18(1), 59-82.

Heydari, J. (2014). Lead time variation control using reliable shipment equipment: An incentive scheme for supply chain coordination. Transportation research part E: Logistics and transportation Review, 63, 44-58. 
Kembro, J., \& Selviaridis, K. (2015). Exploring information sharing in the extended supply chain: an interdependence perspective. Supply Chain Management: An International Journal, 20(4), 455470.

Kim, S., \& Lee, H. (2006). The impact of organizational context and information technology on employee knowledge-sharing capabilities. Public Administration Review, 66(3), 370-385.

Kuzel, A. J. (1992). Sampling in qualitative inquiry.

Lages, C., Lages, C. R., \& Lages, L. F. (2005). The RELQUAL scale: a measure of relationship quality in export market ventures. Journal of business research, 58(8), 1040-1048.

Li, S., \& Lin, B. (2006). Accessing information sharing and information quality in supply chain management. Decision support systems, 42(3), 1641-1656.

Li, S., Rao, S. S., Ragu-Nathan, T. S., \& Ragu-Nathan, B. (2005). Development and validation of a measurement instrument for studying supply chain management practices. Journal of operations management, 23(6), 618-641.

Marshall, M. N. (1996). Sampling for qualitative research. Family practice, 13(6), 522-526.

Martínez-Olvera, C. (2008). Entropy as an assessment tool of supply chain information sharing. European journal of operational research, 185(1), 405-417.

McCormack, K. (1998). What supply chain management practices relate to superior performance. DRK Research Team, Boston, MA, 35-80.

Morse, J. M. (1994). Designing funded qualitative research.

Omar Sharifuddin Syed-Ikhsan, S., \& Rowland, F. (2004). Knowledge management in a public organization: a study on the relationship between organizational elements and the performance of knowledge transfer. Journal of knowledge management, 8(2), 95-111.

Patton, M. Q. (2002).Qualitative research and evaluation methods. Sage Publications Thousand Oaks CA: USA.

Rashed, C. A. A., Azeem, A., \& Halim, Z. (2010). Effect of information and knowledge sharing on supply chain performance: a survey based approach. Journal of Operations and Supply Chain Management, 3(2), 61-77.

Saaty, T. L. (2008). Decision making with the analytic hierarchy process. International journal of services sciences, 1(1), 83-98.

Shore, B., \& Venkatachalam, A. R. (2003). Evaluating the information sharing capabilities of supply chain partners: A fuzzy logic model. International Journal of Physical Distribution \& Logistics Management, 33(9), 804-824.

Skulmoski, G., Hartman, F., \& Krahn, J. (2007). The Delphi method for graduate research. Journal of Information Technology Education: Research, 6(1), 1-21.

Taylor, W. A., \& Wright, G. H. (2004). Organizational readiness for successful knowledge sharing: Challenges for public sector managers. Information resources management journal, 17(2), 22.

Xiao-rong, J., \& Sui-cheng, L. (2010, November). The study on the influencing factors on information sharing and information quality. In Information Management, Innovation Management and Industrial Engineering (ICIII), 2010 International Conference on (Vol. 1, pp. 57-61). IEEE.

Yang, T. M., \& Maxwell, T. A. (2011). Information-sharing in public organizations: A literature review of interpersonal, intra-organizational and inter-organizational success factors. Government Information Quarterly, 28(2), 164-175.

Yang, Z. (2012). A fuzzy ANP-based approach to information sharing capability evaluation of supply chain partners. International Review on Computers and Software, 7(2).

Zailani, S., Premkumar, R., \& Fernando, Y. (2008). Factors influencing the effectiveness of operational information sharing within supply chain channels in Malaysia. Operations and Supply Chain Management, 1(2), 85-100.

Zárraga, C., \& Bonache, J. (2003). Assessing the team environment for knowledge sharing: an empirical analysis. International Journal of Human Resource Management, 14(7), 1227-1245.

Zhou, H., \& Benton, W. C. (2007). Supply chain practice and information sharing. Journal of Operations management, 25(6), 1348-1365. 
194

Zimmermann, H. J. (2011). Fuzzy set theory-and its applications. Springer Science \& Business Media.

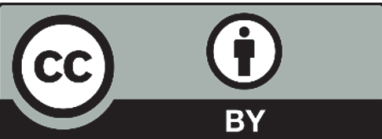

(C) 2018 by the authors; licensee Growing Science, Canada. This is an open access article distributed under the terms and conditions of the Creative Commons Attribution (CC-BY) license (http://creativecommons.org/licenses/by/4.0/). 